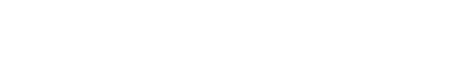

CS 2018.01.01.1

Bionatura Conference Series Vol 1. No 1. 2018

Publicación del IV CONGRESO INTERNACIONAL DE BIOTECNOLOGÍA Y

BIODIVERSIDAD IV CIBB Y XV FORO INTERNACIONAL BANANERO

EDITORIAL

Index / Next

\title{
Innovación y Tecnología para el Agro-Ecuatoriano
}

Daynet Sosa del Castillo

Disponible en: http://dx.doi.org/10.21931/RB/CS/2018.01.01.1

El sector agrícola del país requiere de grandes cambios, de una nueva visión, que le permita enfrentar los desafíos actuales de la región y del mundo, incorporando estrategias en las que la innovación, las nuevas tecnologías y, sobre todo, la sinergia indispensable entre la academia y los productores ecuatorianos, sean fundamentales.

Ecuador, como el resto de los países que tienen Acuerdos de Libre Comercio, necesitan aumentar la productividad de la agricultura en tiempos de cambio climático, de una manera sostenible, a fin de lograr un desarrollo competitivo que sea compatible con la conservación y el manejo adecuado de los recursos naturales, y sobre todo, con la reducción del hambre y de la pobreza, especialmente en zonas rurales.

Enfrentar estos desafíos implica importantes transformaciones, entre ellas las que favorecen la innovación y el cambio tecnológico ya que ambas implican un proceso material y social. Particularmente, es necesario desarrollar y compartir una nueva visión del papel de la investigación y la interacción de los actores que conforman el ecosistema de innovación, para quienes el espacio idóneo de intercambio se encuentra en el marco del IV Congreso Internacional de Biotecnología y Biodiversidad (IV CIBB 2018), promovido por CIBE-ESPOL XV y el Foro Internacional del Banano, promovido por la Asociación de Exportadores de Banano del Ecuador (AEBE),en donde se expusieron nuevas formas de concebir, implementar y conducir los proyectos de investigación y desarrollo (I+D), desde una perspectiva de innovación. 
En esta tercera ocasión, "Innovación y Tecnología para el Agro-Ecuatoriano" fue el lema de los eventos de este año, que se desarrollaron en paralelo del 22 al 25 de octubre en el Hotel Hilton Colón de la ciudad de Guayaquil, donde expertos nacionales e internacionales debatieron temas y problemáticas actuales en torno a la biotecnología y la biodiversidad, con especial énfasis en cultivos emblemáticos del país como el banano, el cacao y el arroz.

IV CIBB 2018 (http://www.cibb.espol.edu.ec) demuestra el esfuerzo que a lo largo de 15 años ha venido realizando la ESPOL en la promoción de la biotecnología ecuatoriana; y fue la continuación de los Congresos I CIBB 2012, II CIBB 2014 y III CIBB 2016, igualmente heredero de una elevada calidad y excelencia académica. El evento contuvo 3 sesiones que acogieron a 3 simposios, 4 foros y 4 cursos pre y post congreso

Con la participación de 31 expertos nacionales y 44 internacionales, de 15 Universidades nacionales y más de 150 asistentes, entre estudiantes, docentes e investigadores, presentamos al país los últimos avances en materia de biotecnología, dejando una vez más nuestra huella en el desarrollo de un agro sostenible, convencidos de que una producción sana y con altos estándares de calidad es esencial para la economía y el desarrollo de todo un país, así como para su soberanía alimentaria.

Si bien el tema central y compartido con el Foro internacional del banano fueron los avances en la mejora genética del cultivo y la importancia del debate nacional sobre un programa nacional de mejora genética, este espacio científico nos permitió también debatir sobre otros productos como el cacao, y temas esenciales para el sector productivo como los procesos de fermentación para la obtención del chocolate. Abordamos también las problemáticas del arroz desde el punto de vista agrícola y comercial, y pusimos a disposición del público nuestros logros en materia de fertilizantes orgánicos.

En general, la investigación, la transferencia de conocimiento y la vinculación de la empresa privada como un aliado de la academia, fueron características esenciales de esta edición del CIBB. Por primera vez logramos un encuentro entre científicos dedicados a la biotecnología agrícola, en un "Science match" que nos ayudó a conectar a la ciencia y a la empresa privada, pues como CIBE somos portadores de soluciones para los desafíos del sector productivo. Aunado a ello, la realización de la II reunión de socios de la red CYTED-BIOALI, permitió establecer un enlace internacional no solo entre académicos sino también, de empresarios extranjeros y nacionales que apuestan por la incorporación cada vez mayor de la biotecnología, en el sector cacao y banano. 
La concurrencia de estudiantes e investigadores en nuestras salas nos permitió saber que fueron temas de gran interés para el sector agrícola y científico, y que el congreso se está transformando en una tradición en Ecuador.

Una de las razones para ello fue contar con expositores de altísimo nivel, 3 de ellos auspiciados por la red CEDIA. Fue un placer tener en nuestro staff a investigadoras como Paloma Moncaleán, de la empresa española Neiker Tecnalia, quien brindó su charla magistral Biotecnología forestal: Hacia los Súper árboles del futuro, un proyecto de larga duración que busca anticiparse a los cambios climáticos y generar especies arbóreas capaces de crecer de forma saludable en condiciones de estrés, como exceso de sol o poca agua. Además, expertas como Blondy Canto, quien se refirió a la producción de bioenergía a partir de residuos del banano, y Sandra Sherry, quien abrió un debate sobre los protocolos de cultivo para transgénicos, le dieron lustre al evento.

Por lo demás, algunas de las charlas que concitaron también gran interés fueron el Mejoramiento genético de los plátanos y bananos a través de la inducción de mutaciones, la biotecnología y el mejoramiento convencional; Cultivos orgánicos; Aplicación de métodos científicos para la validación de la etnofarmacología tradicional y su aplicación en la medicina actual.

Finalmente, como novedad, fuimos el escenario de la premier para Ecuador del documental "Food Evolution", organizado por la Asociación de Biotecnología Vegetal Agrícola, Agro-Bio de Colombia, lo cual indujo la realización de un conversatorio sobre la bioseguridad de los Organismos Genéticamente Modificados (GMO) el 30 de octubre del 2018.

En este cuarto año, el CIBB nos ha dejado clara la importancia de ir de la mano con el sector privado para encontrar soluciones a problemas y caminar juntos a la innovación que tanto necesita el país para su desarrollo productivo.

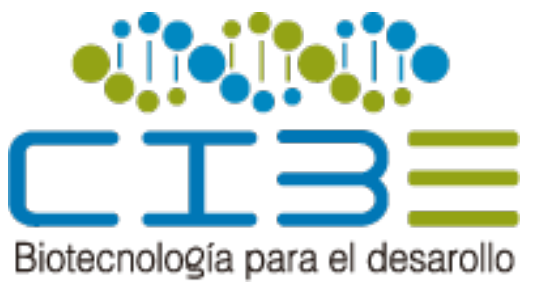

